\title{
Influence of Physical Fitness and Smoking on the Coagulation System in Hypertensive Patients: Effect on Prothrombin Fragment F1+2
}

\author{
Junzo Nagashima ${ }^{1}$, Haruki Musha ${ }^{2}$, Hideomi Takada ${ }^{1}$, Naoki Matsumoto ${ }^{3}$, Rikiya Fujimaki ${ }^{4}$, \\ Narumi Ishige ${ }^{1}$, Jiro Aono ${ }^{1}$ and Masahiro Murayama ${ }^{1}$
}

\begin{abstract}
Object Recently, prothrombin fragment F1+2 was shown to be a sensitive direct marker of thrombin formation. We examined the effect of lifestyle (including physical activity) on prothrombin fragment F1+2 levels. Methods Using the results of a questionnaire, the subjects were classified into groups on the basis of multiple medications, smoking, exercise, and drinking alcohol. The prothrombin fragment F1+2 levels were compared between each pair of groups and differences were analyzed using the unpaired t-test. Correlations between each parameter and the systolic and diastolic blood pressure, as well as with prothrombin fragment $\mathrm{F} 1+2$, were examined by multiple regression analysis.

Patients The subjects were 109 patients who had essential hypertension without a past history of thrombotic events

Results Smokers $(1.47 \pm 0.75$ vs $0.98 \pm 0.46 \mathrm{nmol} / \mathrm{L}, \mathrm{p}<0.0001)$, and those without regular exercise $(1.22 \pm 0.59$ vs $0.68 \pm 0.30 \mathrm{nmol} / \mathrm{L}, \mathrm{p}<0.0001)$ had higher levels of prothrombin fragment $\mathrm{F} 1+2$. Age, lack of exercise, and smoking were significant predictors of a high concentration of prothrombin fragment $\mathrm{F} 1+2$. Of the smokers, the patient with a regular exercise had low $\mathrm{F} 1+2$ compared with those without regular exercise $(0.75 \pm 0.20$ vs $2.01 \pm 0.49 \mathrm{nmol} / \mathrm{L}, \mathrm{p}<0.0001$.

Conclusions In patients with essential hypertension, age, smoking, and lack of regular exercise may increase the risk of thrombosis. Even in smokers, a regular exercise routine may reduce the tendency towards thrombus formation.
\end{abstract}

Key words: hypertension, lifestyle, smoking, F1+2, exercise

(DOI: 10.2169/internalmedicine.46.6465)

\begin{tabular}{l} 
Introduction \\
\hline Many studies have demonstrated the efficacy of physical \\
fitness for preventing cardiovascular disease and the cost- \\
effectiveness of exercise (1-5). Prothrombin fragment F1+2 \\
was shown to be a sensitive direct marker of thrombin for- \\
mation (6). In the present study, we examined the effect of \\
lifestyle, including the level of physical activity, on \\
prothrombin fragment $\mathrm{F} 1+2$.
\end{tabular}

\section{Introduction}

\footnotetext{
${ }^{1}$ Internal Medicine Section, Yokohama City Sports Medical Center, Yokohama, ${ }^{2}$ Department of Cardiology, St. Marianna University School of Medicine, Yokohama City Seibu Hospital, Yokohama, ${ }^{3}$ Department of Pharmacology, St. Marianna University School of Medicine, Kawasaki and ${ }^{4}$ Department of Internal Medicine, Sun-Toranomon Clinic, Tokyo

Received for publication December 26, 2006; Accepted for publication February 26, 2007

Correspondence to Dr. Junzo Nagashima, junagashima-circ@umin.ac.jp
}

Subjects

The subjects were 109 patients with well controlled essential hypertension (the mean blood pressure in an automatic ambulatory monitor was $140 \mathrm{mmHg}$ or less in systole and $90 \mathrm{mmHg}$ or less in diastole) who had no complications (no hyperlipidemia or diabetes mellitus) and no past history of thrombotic events (including elevation of D-dimer levels). Written informed consent for this study was obtained from all subjects. Approval of the study was also obtained from 

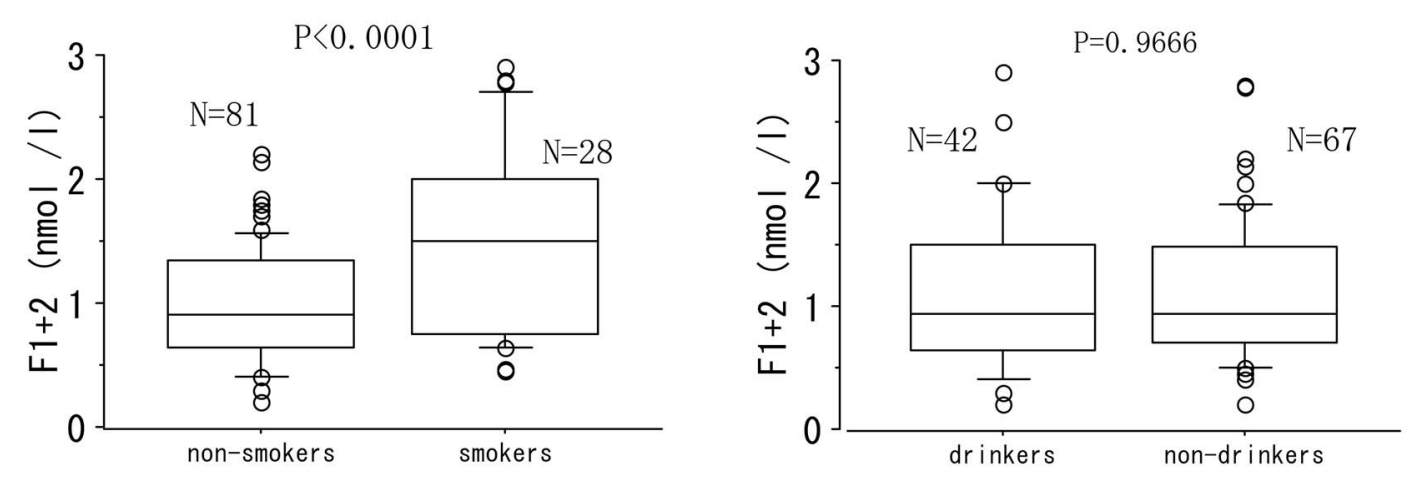

$\mathrm{P}<0.0001$
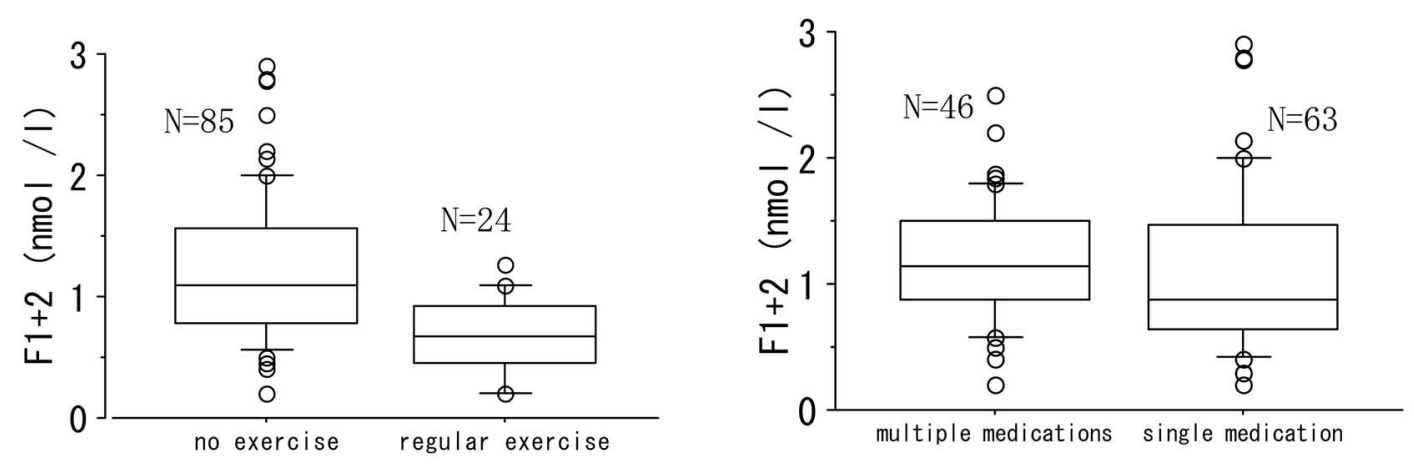

Figure 1. The prothrombin fragment F1+2 levels of each pair of groups.

the research ethics committee of St. Marianna University School of Medicine.

\section{Methods}

The blood concentration of prothrombin fragment F1+2 was measured using sandwich enzyme immunoassay method (Enzygnost F1+2, Höchst, Frankfurt.). From the results of a questionnaire, the subjects were classified into pairs of groups based on the number of medications taken, smoking status, exercise, and alcohol intake. Regular exercise was defined as physical activity for more than 30 minutes per day or manual labor, and habitual drinking was defined as an intake of more than $20 \mathrm{~g}$ of ethanol per day. The prothrombin fragment F1+2 levels were compared between each pair of groups and differences were analyzed using the unpaired t-test. Correlations of the systolic and diastolic blood pressure, body mass index, and other parameters with the prothrombin fragment $\mathrm{F} 1+2$ levels were examined by multiple regression analysis. A probability value $<0.05$ was considered significant. Statistical analysis was done on an Apple Macintosh computer (Japan Apple Computer, Inc., Tokyo, Japan), with the Stat View 5.0 program (SAS Institute, Inc., Cary, NC).

\section{Results}

Smokers $(1.47 \pm 0.75$ vs $0.98 \pm 0.46 \mathrm{nmol} / \mathrm{L}, \mathrm{p}<0.0001$ and those without regular exercise $(1.22 \pm 0.59$ vs $0.68 \pm$ $0.30 \mathrm{nmol} / \mathrm{L}, \mathrm{p}<0.0001)$ had higher levels of prothrombin
Table 1. Predictors of a Higher Concentration Prothorombin Fragment F1+2

\begin{tabular}{llr}
\hline & $\beta$ & $\mathrm{p}$ \\
\hline Age & 0.314 & $<0.0001$ \\
Smoking(+) & 0.589 & $<0.0001$ \\
Regular exercise & -0.524 & $<0.0001$ \\
Systolic blood pressure & 0.027 & 0.7311 \\
Diastolic blood pressure & -0.106 & 0.1883 \\
Body mass index & 0.002 & 0.8947 \\
\hline
\end{tabular}

fragment F1+2 (Fig. 1). There were no significant differences in body mass index and other parameters between the pairs of groups.

Multiple regression analysis using the concentration of prothrombin fragment $\mathrm{F} 1+2$ as the dependent variable versus age, systolic blood pressure, diastolic blood pressure, body mass index, smoking and exercise as independent variables showed that age, smoking, and lack of regular exercise were significant predictors of a higher concentration of prothrombin fragment $\mathrm{F} 1+2(\mathrm{p}<0.0001)$ (Table 1).

Of the smokers, the patients who undertook regular exercise had low F1+2 compared with those without regular exercise $(0.75 \pm 0.20$ vs $2.01 \pm 0.49 \mathrm{nmol} / \mathrm{L}, \mathrm{p}<0.0001)$ (Fig. 2).

\section{Discussion}

Various coagulation markers are being investigated as risk 


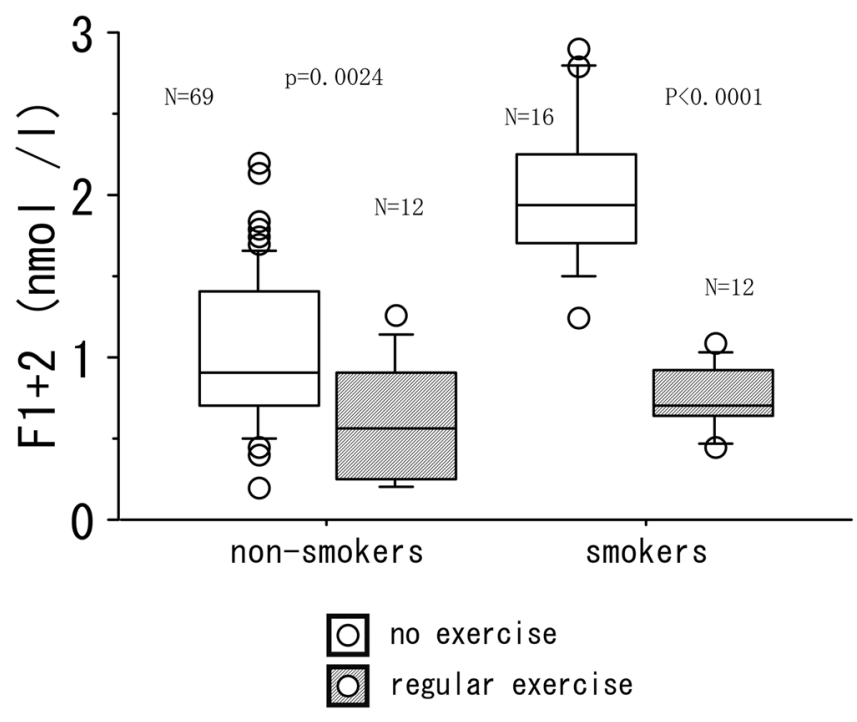

Figure 2 The prothrombin fragment F1+2 levels of smokers.

factors for cardiovascular disease. During the process of coagulation, prothrombin fragment $\mathrm{F} 1+2$ is generated when prothrombin is activated to form thrombin by the prothrombinase complex. As a marker of thrombin formation, F1+2 has clinical utility for assessing the risk of thrombosis and for monitoring the efficacy of anticoagulant therapy (7). Daily physical activity was suggested to prevent various thrombo-embolic events examined in a cross-sectional study in a previous report (8). Additionally, it is well established that physical exercise may improve metabolic status.

In this study, we examined the influence of several lifestyle factors on the plasma level of prothrombin fragment F1+2 in hypertensive patients. Smoking, alcohol, exercise, and use of multiple medications were all examined. We found that age, smoking, and lack of regular exercise were significant predictors of a higher concentration of prothrom- bin fragment $F 1+2$. Previous reports regarding predictors of a higher concentration of $\mathrm{F} 1+2$ showed positive associations with age (9), sex (9), smoking $(9,10)$, race (9), and a history of ischemic heart disease (11). The relationship between lifestyle and the concentration of F1+2 was also assessed in the Caerphilly study (12), showing that smoking was a positive predictor of a higher concentration of $\mathrm{F} 1+2$, but so was leisure and work activity. In the Caerphilly study, leisure activity only showed a negative association with Ddimer levels. This difference between our findings and those of the Caerphilly study may result from the selection of subjects since the Caerphilly study was population-based and our study only assessed hypertensive patients.

Additionally, we found that regular exercise may reduce the tendency for thrombus formation even in smokers. This finding supports the health benefits of exercise in hypertensive smokers.

\section{Study Limitations}

The important limitations of this study are the small number of subjects and the fact that we did not evaluate other coagulation factors. In the future, investigation of other parameters, including hemolytic factors, and clinical outcome observation should be performed.

\section{Conclusions}

In patients with essential hypertension, smoking and lack of regular exercise may increase the risk of thrombosis. Regular exercise may reduce the tendency for thrombus formation even in hypertensive smokers.

Part of this article was presented at the 64th and 65th annual meetings of the Japanese Circulation Society.

\section{References}

1. Hakim AA, Curb JD, Petrovitch H, et al. Effects of walking on coronary heart disease in elderly men: the Honolulu Heart Program. Circulation 100: 9-13, 1999.

2. Paffenbarger RS Jr, Hyde RT, Wing AL, Hsieh CC. Physical activity, all-cause mortality, and longevity of college alumni. N Engl J Med 314: 605-613, 1986.

3. Paffenbarger RS Jr, Hyde RT, Wing AL, Steinmetz CH. A natural history of athleticism and cardiovascular health. JAMA 252: 491495, 1984.

4. Paffenbarger RS Jr, Kampert JB, Lee IM, Hyde RT, Leung RW, Wing AL. Changes in physical activity and other lifeway patterns influencing longevity. Med Sci Sports Exerc 26: 857-865, 1994.

5. Bauer KA, Rosenberg RD. The pathophysiology of the prethrombotic state in humans: insights gained from studies using markers of hemostatic system activation. Blood 70: 343-350, 1987.

6. Pelzer H, Schwarz A, Stuber W. Determination of human prothrombin activation fragment $1+2$ in plasma with an antibody against a synthetic peptide. Thromb Haemost 65: 153-159, 1991.

7. Rugman FP, Jenkins JA, Duguid JK, Maggs PB, Hay CR. Prothrombin fragment $\mathrm{F} 1+2$ : correlations with cardiovascular risk factors. Blood Coagul Fibrinolysis 5: 335-340, 1994.

8. van der Burg PJ, Hospers JE, van Vliet M, Mosterd WL, Bouma BN, Huisveld IA. Changes in haemostatic factors and activation products after exercise in healthy subjects with different ages. Thromb Haemost 74: 1457-1464, 1995.

9. Hursting MJ, Stead AG, Crout FV, Horvath BZ, Moore BM. Effects of age, race, sex, and smoking on prothrombin fragment 1.2 in a healthy population. Clin Chem 39: 683-686, 1993. 
DOI: $10.2169 /$ internalmedicine.46.6465

10. Miller GJ, Bauer KA, Cooper JA, Rosenberg RD. Activation of the coagulant pathway in cigarette smokers. Thromb Haemost 79: 549-553, 1998.

11. Musial J, Pajak A, Undas A, et al. Thrombin generation markers and coronary heart disease risk factors in a Polish population sam- ple. Thromb Haemost 77: 697-700, 1997.

12. Yarnell JW, Sweetnam PM, Rumley A, Lowe GD. Lifestyle factors and coagulation activation markers: the Caerphilly Study. Blood Coagul Fibrinolysis 12: 721-728, 2001.

(C) 2007 The Japanese Society of Internal Medicine http://www.naika.or.jp/imindex.html 